\title{
Experimental design for optimization of microwave-assisted extraction of benzodiazepines in human plasma
}

\author{
P. Fernández • C. Vázquez $\cdot$ R. A. Lorenzo • \\ A. M. Carro • I. Álvarez • P. Cabarcos
}

Received: 4 November 2009 /Revised: 22 December 2009/Accepted: 11 February 2010/Published online: 5 March 2010

(C) Springer-Verlag 2010

\begin{abstract}
A simple and fast microwave-assisted-extraction (MAE) method has been evaluated as an alternative to solid-phase extraction (SPE) for the determination of six benzodiazepines widely prescribed in European countries (alprazolam, bromazepam, diazepam, lorazepam, lormetazepam and tetrazepam) in human plasma. For MAE optimization a Doehlert experimental design was used with extraction time, temperature and solvent volume as influential parameters. A desirability function was employed in addition to the simultaneous optimization of the MAE conditions. The analysis of variance showed that the solvent volume had a positive influence on the extraction of all the analytes tested, achieving a statistically significant effect. Also, the extraction time had a statistically significant effect on the extraction of four benzodiazepines. The selected MAE conditions $-89^{\circ} \mathrm{C}, 13 \mathrm{~min}$ and $8 \mathrm{~mL}$ of chloroform $/ 2$ propanol $(4: 1, \mathrm{v} / \mathrm{v})$-led to recoveries between $89.8 \pm 0.3$ and $102.1 \pm 5.2 \%$ for benzodiazepines using a high performance liquid chromatography method coupled with diode-array detection. The comparison of MAE and SPE shows better results for MAE, with a lower number of steps in handling the sample and greater efficiency. The applicability of MAE was successfully tested in 27 plasma samples from benzodiazepine users.
\end{abstract}

P. Fernández $(\triangle) \cdot$ C. Vázquez $\cdot$ I. Álvarez $\cdot$ P. Cabarcos Institute of Legal Medicine, Forensic Toxicology Service, Faculty of Medicine,

15782 Santiago de Compostela, Spain

e-mail: puri.fernandez@usc.es

R. A. Lorenzo · A. M. Carro

Department of Analytical Chemistry, Faculty of Chemistry, 15782 Santiago de Compostela, Spain
Keywords Benzodiazepines $\cdot$ Human plasma Microwave-assisted extraction · Experimental design . High-performance liquid chromatography-diode-array detection

\section{Introduction}

In the short term, benzodiazepines (BZD) are remarkably useful psychoactive drugs, highly effective for disorders such as anxiety, epilepsy and insomnia. However, serious adverse effects can result from long-term regular use in therapeutic doses and from self-prescription or recreational use in excessive doses. The combined disinhibitory effects of alcohol and BZD may also be additive and contribute to aggressive behaviour. Sexual offences and acts of violence (both homicide and suicide) can be related to BZD consumption and can lead to medicolegal complications $[1,2]$.

The risk of dependence is probably greater with potent, short-acting BZD such as lorazepam and alprazolam. Caution should be exercised in prescribing BZD hypnotics and anxiolytics because they may also induce dependence if used long-term [1]. Quantification in plasma may help to optimize chronic dosing, verify compliance and identify changes in pharmacokinetics [3]. For these reasons, the optimization of reliable, rapid and simple methods for the control of BZD in plasma is required to save time and cost, without losing the sensitivity and reproducibility of the analytical method.

Liquid chromatography has become an important tool for routine determination of BZD owing to its specificity, rapidity and sensitivity [4-8]. Although high-performance liquid chromatography (HPLC) with mass spectrometry detection [5-7] is highly selective, the cost of the instrumentation makes it less suitable for clinical or toxicology laboratories. In contrast, HPLC-UV detection or diode array detection 
(DAD) instrumentation is widely available in most analytical laboratories [8-12].

An effective sample pretreatment procedure prior to HPLC separation is often necessary to improve sensitivity. Liquidliquid extraction [13], solid-phase extraction (SPE) [14-16], online SPE [17] and solid-phase microextraction [18] have usually been successfully employed. Different analytical methods have been effectively developed and established to both identify and quantify these compounds; relevant information on a selected number of BZD-based applications is presented in Table 1. Similar limits of detection (LODs) at the nanogram per millilitre level have been achieved with different detection systems used with gas chromatography or HPLC separation.

Microwave-assisted extraction (MAE) is very suitable for routine analysis, without any additional cleaning step, giving greater efficiency of the method. Furthermore, MAE enables simultaneous extractions producing less waste than other conventional techniques; therefore, it is considered a clean technology (green chemistry). There are a large number of reports concerning application of this technique in environmental sample analysis [34, 35]. MAE has also been used successfully in analysis of medicines, vitamins and drugs of abuse, present in pharmaceutical and biological samples [36, 37].

Factorial designs, which provide a method for simultaneously investigating the effects of multiple variables and multiple responses, have generally been used and preferred to the one factor at a time approach because they detect and estimate any interaction among variables and need fewer experiments to complete the optimization process [38].

Table 1 Methods for the determination of benzodiazepines $(B Z D)$

\begin{tabular}{|c|c|c|c|c|c|}
\hline Matrix & Analytes & Pretreatment/extraction & Determination & LOD & Reference \\
\hline $\begin{array}{l}\text { Urine, plasma, } \\
\text { serum, meconium }\end{array}$ & 10 BZD & $\begin{array}{l}\text { Hydrolysis/SPE Trace-B columns/ethyl } \\
\text { acetate/ammonium hydroxide elution }\end{array}$ & LC-ESI-MS/MS & $10 \mathrm{ng} \mathrm{mL}^{-1}$ & {$[3]$} \\
\hline Blood & $33 \mathrm{BZD}$ & $\begin{array}{l}\text { SPE ChemElut cartridges/t-butyl } \\
\text { methyl ether }\end{array}$ & LC-APCI-MS & $0.1-12.6 \mathrm{ng} \mathrm{mL}^{-1}$ & {$[6]$} \\
\hline Plasma & 15 BZD & SPE $\mathrm{C}_{1}$ cartridges $/ \mathrm{MeOH}$ elution & HPLC-UV & $2.6 \mathrm{ng} \mathrm{mL}^{-1}$ & {$[8]$} \\
\hline Urine, plasma, saliva & $8 \mathrm{BZD}$ & $\begin{array}{l}\text { SPE Abselut Nexus } \\
\text { cartridges/MeOH/ACN }\end{array}$ & HPLC-DAD & $20-47 \mathrm{ng} \mathrm{mL} \mathrm{L}^{-1}$ & [9] \\
\hline Urine, plasma & $4 \mathrm{BZD}$ & SPE DSC-18 cartridges $/ \mathrm{MeOH}$ elution & HPLC-UV & $100-600 \mathrm{ng} \mathrm{mL}^{-1}$ & [19] \\
\hline Rat plasma & FNZ and metabolites & LLE Toxi-Tubes A/BSTFA derivatization & GC-MS & $125 \mathrm{ng} \mathrm{mL}^{-1}$ & {$[20]$} \\
\hline Serum, urine & $4 \mathrm{BZD}$ & $\begin{array}{l}\text { SPE Abselut Nexus and Oasis HLB } \\
\text { cartridges/ethyl ether elution }\end{array}$ & HPLC-UV & $1.0 \mathrm{ng} \mathrm{mL}^{-1}$ & {$[21]$} \\
\hline Plasma and oral fluid & $9 \mathrm{BZD}$ & LLE/diethyl ether & LC-ESI-MS & $0.5-1 \mathrm{ng} \mathrm{mL}{ }^{-1}$ & {$[22]$} \\
\hline Blood & $14 \mathrm{BZD}$ & LLE with ACN/MTBSTFA derivatization & GC-NICI-MS & $1-100 \mathrm{ng} \mathrm{mL}^{-1}$ & {$[23]$} \\
\hline Urine and blood & FNZ and metabolites & $\begin{array}{l}\text { LLE-SPE CECN4 butyl cartridges/ } \\
\text { ethyl acetate/methanol elution }\end{array}$ & $\begin{array}{l}\text { TFA derivatization- } \\
\text { HPLC-DAD/PFPA } \\
\text { derivatization-GC- } \\
\text { SIM-MS }\end{array}$ & $1-5 \mathrm{ng} \mathrm{mL}^{-1}$ & {$[24]$} \\
\hline Hair & 14 BZD & LLE/diethyl ether/DCM & LC-ESI-MS/MS & $0.5-5 \mathrm{pg} \mathrm{mg}^{-1}$ & {$[25]$} \\
\hline Soil & $3 \mathrm{BZD}$ & SPE Phenomenex Strata-X/MeOH elution & HPLC-ESI-MS & - & {$[26]$} \\
\hline Hair & $9 \mathrm{BZD}$ & $\begin{array}{l}\text { SPE Clean Screen columns/ammoniated } \\
\text { ethyl acetate elution } \\
\text { MISPE/acetic acid in acetonitrile elution }\end{array}$ & LC-ESI-MS/MS & $30-780 \mathrm{pg} \mathrm{mg}^{-1}$ & {$[27]$} \\
\hline Urine & $11 \mathrm{BZD}$ & SPE extract-clean column $\mathrm{C}_{18} / \mathrm{MeOH}$ & LC-ESI-MS/MS & $30 \mathrm{ng} \mathrm{mL}^{-1}$ & {$[28]$} \\
\hline Serum & $30 \mathrm{BZD}$ & SPE Oasis MCX cartridges/ACN & LC-ESI-MS & $0.1-5 \mathrm{ng} \mathrm{mL}^{-1}$ & [29] \\
\hline Urine and plasma & $4 \mathrm{BZD}$ & Automated online SPE Empore ${ }^{\mathrm{TM}}$ disks & LC-ESI-MS/MS & $0.02-0.15 \mathrm{ng} \mathrm{mL}^{-1}$ & {$[30]$} \\
\hline Urine and hair & $2 \mathrm{BZD}$ & LLE Toxi-Tubes A/DCM & LC-ESI-MS/MS & $\begin{array}{l}0.05-01 \mathrm{ng} \mathrm{mL}^{-1} \\
0.5-2 \mathrm{pg} \mathrm{m}^{-1}\end{array}$ & [31] \\
\hline Oral fluid & $8 \mathrm{BZD}$ & LLE Toxi-Tubes A & LC/MS/MS & $0.2-2.1 \mathrm{ng} \mathrm{mL}^{-1}$ & {$[32]$} \\
\hline Plasma & $6 \mathrm{BZD}$ & $\begin{array}{l}\text { SPE Bond Elut Certify } \\
\text { cartridges/chloroform/2-propanol } \\
\text { elution }\end{array}$ & HPLC-DAD & $7.6-14 \mathrm{ng} \mathrm{mL}^{-1}$ & {$[33]$} \\
\hline
\end{tabular}

$A C N$ acetonitrile, $A P C I$ atmospheric pressure chemical ionization, BSTFA N,O-bis(trimethylsilyl)trifluoroacetamide, $D A D$ diode-array detection, $D C M$ dicloromethane, $E S I$ electrospray injection, $F N Z$ flunitrazepam, $G C$ gas chromatography, $H P L C$ high-performance liquid chromatography, $L C$ liquid chromatography, LLE liquid-liquid extraction MISPE molecularly imprinted solid-phase extraction, MS mass spectrometry, MTBSTFA $\mathrm{N}$-methyl- $\mathrm{N}$-(trimethylsilyl)- $\mathrm{N}, \mathrm{O}$-bis(trimethylsilyl) trifluoroacetamide, $\mathrm{NICI}$ negative ion chemical ionization, PFPA pentafluoropropionic anhydride, SIM selected ion monitoring, SPE solid-phase extraction, TFA trifluoroacetic acid, UV UV detection 
The aim of this study was to determine the applicability of MAE as an alternative to established procedures, such as SPE, for the simultaneous extraction of six frequently prescribed BZD in human plasma - alprazolam, bromazepam, diazepam, lorazepam, lormetazepam and tetrazepam - with the therapeutic and toxic levels shown in Table 2. The development of a feasible and reliable HPLC-DAD method based on microwave extraction for BZD in plasma at concentrations lower than therapeutic levels was performed and validated using spiked samples. The method was applied to the analysis of real plasma samples from BZD users.

\section{Experimental}

\section{Chemicals}

Standards of the BZD studied were obtained from Cerilliant (Round Rock, TX, USA). Gradient-grade acetonitrile, chloroform, 2-propanol and methanol were purchased from Merck (Darmstadt, Germany). Purified water was obtained from a Milli-Q water system from Millipore (Le Mont-surLausane, Switzerland). Individual stock solutions containing $1 \mathrm{mg} \mathrm{mL}^{-1}$ of each drug were prepared in methanol. Workingstrength solutions containing the six BZD were made by successive dilutions of the stock solutions to obtain final concentrations within the range $0.06-2 \mu \mathrm{g} \mathrm{mL} \mathrm{m}^{-1}$ in plasma. All solutions were stored frozen. Bond Elut Certify cartridges were obtained from Varian ${ }^{\circledR}$ (Walnut Creek, CA, USA).

\section{Instrumentation}

The microwave extraction device was an ETHOS PLUS MPR300/12 S from Milestone ${ }^{\circledR}$ (Agrigento, Italy) equipped with a solvent detector. The device was able to extract 12 samples simultaneously in PTFE-lined extraction closed vessels under the same conditions (temperature and pressure), with simultaneous magnetic stirring of the sample and solvent. An on-board pressure control system

Table 2 Therapeutic and toxic levels of BZD

\begin{tabular}{lll}
\hline BZD & Therapeutic levels $(\mu \mathrm{g} / \mathrm{mL})$ & Toxic levels $(\mu \mathrm{g} / \mathrm{mL} /$ \\
\hline APZ & $0.025-0.10$ & $0.10-0.40$ \\
BRZ & $0.11-0.17$ & - \\
DZP & $0.10-1.00$ & $>1.5$ \\
LRZ & $0.05-0.24$ & $0.30-0.60$ \\
LRMZ & $0.006-0.016$ & - \\
TRZ & $0.49-0.63$ & -
\end{tabular}

Data from [39]

$A P Z$ alprazolam, $B R Z$ bromazepam, $D Z P$ diazepam, $L R Z$ lorazepam, LRMZ lormetazepam, TRZ tetrazepam was installed for monitoring and controlling the pressure and conditions inside the extraction vessels. This oven allows a maximum power of $1,000 \mathrm{~W}$ and the power changes to reach and maintain the temperature selected.

Analyses were carried out with a Waters ${ }^{\circledR}$ (Milford, MA, USA) 2695 chromatograph connected to a model 996 photodiode array detector, also from Waters ${ }^{\circledR}$. Data were processed with the Millennium $32^{\circledR}$ software program. Samples were injected into an XTerra ${ }^{\circledR}$ RP8 $(250 \mathrm{~mm} \times$ 4.6-mm inner diameter, $5-\mu \mathrm{m}$ particle size) stainless steel column from Waters ${ }^{\circledR}$.

To ensure optimal peak resolution, and hence the efficient separation of the analytes in a reasonably short time (28 min), elution was done with a mobile phase consisting of a mixture of acetonitrile (solvent A) and $0.02 \mathrm{M}$ phosphate buffer $\mathrm{pH} 7.5$ (solvent B), at a flow of $0.8 \mathrm{~mL} / \mathrm{min}$, in gradient mode: $0-12 \mathrm{~min}, 35 \%$ solvent $\mathrm{A}$ and $65 \%$ solvent $\mathrm{B} ; 14-30 \mathrm{~min}, 40 \%$ solvent $\mathrm{A}$ and $60 \%$ solvent B; $35 \mathrm{~min}, 35 \%$ solvent A and $65 \%$ solvent $\mathrm{B}$. The diode-array detector allowed the wavelength range from 200 to $400 \mathrm{~nm}$ to be scanned to obtain three-dimensional (wavelength $\mathrm{x}$ absorbance $\mathrm{x}$ time) chromatograms, although we decided to work at $230 \mathrm{~nm}$, a wavelength very near the absorption maxima of the six BZD, which permits a good simultaneous chromatographic response to be obtained.

\section{Plasma samples}

Drug-free plasma from the Galician Transfusion Centre (Spain) was used for the preparation of calibration standards. Plasma samples were obtained from patients poisoned with BZD and stored at $4{ }^{\circ} \mathrm{C}$, unless the analysis was delayed, in which case the samples were frozen. All studies were conducted in accordance with the World Medical Association's "Ethical principles for medical research involving human subjects" [40].

\section{MAE procedure}

The plasma was centrifuged in a MiniSpin Plus centrifuge (Eppendorf ${ }^{\circledR}$ ) for $10 \mathrm{~min}$ at $14,000 \mathrm{rpm}$ to eliminate compounds that could be coextracted, causing a matrix effect. The MAE conditions were optimized for the extraction of BZD from human plasma as discuss in "Results and discussion". The final optimized procedure was as follows. Borate buffer $(2 \mathrm{~mL}, \mathrm{pH} 9.0)$ was added to $1 \mathrm{~mL}$ of plasma containing the analytes and the samples were extracted at $89{ }^{\circ} \mathrm{C}$ for $13 \mathrm{~min}$, using $8 \mathrm{~mL}$ of chloroform/2-propanol $(4: 1, \mathrm{v} / \mathrm{v})$. After cooling, the extraction vessels were opened and the extracts were centrifuged for $10 \mathrm{~min}$ at $4,000 \mathrm{rpm}$ to separate the organic phase from the aqueous one. The supernatant was collected and concentrated to dryness under a nitrogen stream at $40{ }^{\circ} \mathrm{C}$. 
The extracts were redissolved in $200 \mu \mathrm{L}$ of the mobile phase, yielding a concentration 5 times higher than that originally present in plasma. After ultracentrifugation for $5 \mathrm{~min}$ at $14,000 \mathrm{rpm}, 20 \mu \mathrm{L}$ of the supernatant was injected into the chromatograph.

\section{SPE procedure}

The method used for the SPE has been robustly validated and a full description of the procedure has been reported elsewhere [33]. In brief, $500 \mu \mathrm{L}$ of borate buffer $\mathrm{pH} 9.0$ was added to $500 \mu \mathrm{L}$ of the sample containing the BZD. The drugs were separated from plasma with Manifold (Waters ${ }^{\circledR}$ ) and Bond Elut Certify cartridges, which were conditioned with $2 \mathrm{~mL}$ of methanol and $2 \mathrm{~mL}$ of phosphate buffer $\mathrm{pH}$ 6.0. The sample was added and washed with $3 \mathrm{~mL}$ of water/methanol $(95: 5, \mathrm{v} / \mathrm{v})$ and $3 \mathrm{~mL}$ of $0.3 \mathrm{M}$ $\mathrm{NH}_{4} \mathrm{OH}$. The samples were then vacuum-dried for $5 \mathrm{~min}$, being eluted with $3 \mathrm{~mL}$ of chloroform/2-propanol (4:1, v/v). The extracts obtained were evaporated under a nitrogen stream at $40{ }^{\circ} \mathrm{C}$ and reconstituted in $200 \mu \mathrm{L}$ of the mobile phase, yielding a concentration 2.5 times higher than that originally present in plasma. Finally, $20 \mu \mathrm{L}$ was injected into the chromatograph.

\section{Validation procedure}

The procedure was validated in terms of linearity, repeatability (intraday precision), reproducibility (interday precision) and recovery. In view of the therapeutic and toxic concentrations, calibration curves were generated by spiking blank plasma. The calibration curve was established at six concentrations in the range $60-2,000 \mathrm{ng} \mathrm{mL}^{-1}$. Precision was characterized in terms of the relative standard deviation (RSD) by analysing sets of five spiked human plasma samples at three different concentrations $\left(0.06,0.4\right.$, and $\left.2 \mu \mathrm{g} \mathrm{mL}^{-1}\right)$. Recovery of the sample was determined by $n=5$ analyses of samples spiked at three concentrations $\left(0.06,0.4\right.$ and $\left.2 \mu \mathrm{g} \mathrm{mL}^{-1}\right)$.

\section{Results and discussion}

\section{Preliminary experiments}

To evaluate the solvent effect on the extraction of BZD from human plasma, studies were performed using different solvents and mixtures commonly employed in traditional extraction of drugs from biological matrices: (1) $n$-hexane; (2) dichloromethane; (3) ethyl acetate; (4) chloroform; (5) chloroform/methanol (1:1, v/v); (6) chloroform/2-propanol $(1: 4, \mathrm{v} / \mathrm{v}, 1: 1, \mathrm{v} / \mathrm{v}$ and $4: 1, \mathrm{v} / \mathrm{v})$. For MAE, the solvent used as an extractant requires good permittivity to absorb the microwave energy and transform it into thermal energy.
The aqueous matrix of plasma locally superheats the analytes and promotes their release into the surrounding medium. Moreover, the high temperatures reached by microwave heating substantially reduce both the extraction time and the required solvent volume [41]. In all cases $1 \mathrm{~mL}$ of blank plasma was spiked with $1 \mu \mathrm{g}$ of all BZD studied. MAE was performed using the following general conditions: $10 \mathrm{~mL}$ of solvent and $6 \mathrm{~min}$ at $80^{\circ} \mathrm{C}$. Figure 1 shows the effect of solvent or solvent mixtures on the extraction of the target analytes from spiked samples. Hexane and dichloromethane gave worse results than the other solvents. Hexane is not capable of extracting alprazolam, bromazepam and lorazepam, whereas bromazepam is not extracted when dichloromethane is used. Chloroform/2propanol $(1: 1, \mathrm{v} / \mathrm{v}$ and $1: 4, \mathrm{v} / \mathrm{v})$ mixtures provided extraction yields lower than those found for chloroform for the majority of the compounds studied. Chloroform/2-propanol $(4: 1, \mathrm{v} / \mathrm{v})$ provided the best extraction results for all the BZD and was chosen as the extractant.

Plasma samples were mixed with a volume of borate buffer $\mathrm{pH} 9.0$ to ensure that BZD were in a nonionized form and they could easily switch to the organic phase. Additions of 1, 2 or $4 \mathrm{~mL}$ of buffer to $1 \mathrm{~mL}$ of plasma were evaluated using the general MAE conditions described above: $10 \mathrm{~mL}$ of chloroform/2-propanol (4:1, v/v), $6 \mathrm{~min}$ and $80{ }^{\circ} \mathrm{C}$. The $1: 2$ ratio mixture gave the best extraction responses for all BZD.

\section{Optimization of the MAE procedure}

Temperature, extraction time and extracting solvent volume were simultaneously optimized through a uniform shell (Doehlert) design comprising 12 experiments and three central points [38]. In the experimental domain, five different temperatures $\left(60,75,90,105\right.$ and $\left.120^{\circ} \mathrm{C}\right)$, seven times $(2,4,5,7,9,10$ and $12 \mathrm{~min})$ and three solvent volumes $(4,7$ and $10 \mathrm{~mL})$ were tested. The design was performed randomly to avoid the influence of external conditions. For each BZD a quadratic polynomial model was considered:

$y=b_{0}+\sum_{i=1}^{n} b_{i} x_{i}+\sum_{i=1}^{n} \sum_{j=1}^{n} b_{i j} x_{i} x_{j}$

where $x_{i}$ is the coded value of the factors studied (extraction temperature, time and solvent volume) and $y$ is the response (peak area) obtained for each BZD. The $b$ values are the estimated polynomial coefficients: $b_{0}$ is the intercept term, $b_{i}$ coefficients represent the main effect for each variable, $b_{i j}$ coefficients in the quadratic terms are responsible for the curvature effects and $b_{i j(i \neq j)}$ coefficients describe the interaction effects. Experimental design generation and all statistical analyses were carried out using the Nemrod $($ W 
Fig. 1 Concentrations obtained with different extraction solvents tested. $A P Z$ alprazolam, $B R Z$ bromazepam, $D Z P$ diazepam, $L R Z$ lorazepam, $L R M Z$ lormetazepam, TRZ tetrazepam, HEX $n$-hexane, $D C M$ dichloromethane, CHLORF chloroform, ISOPR 2-propanol

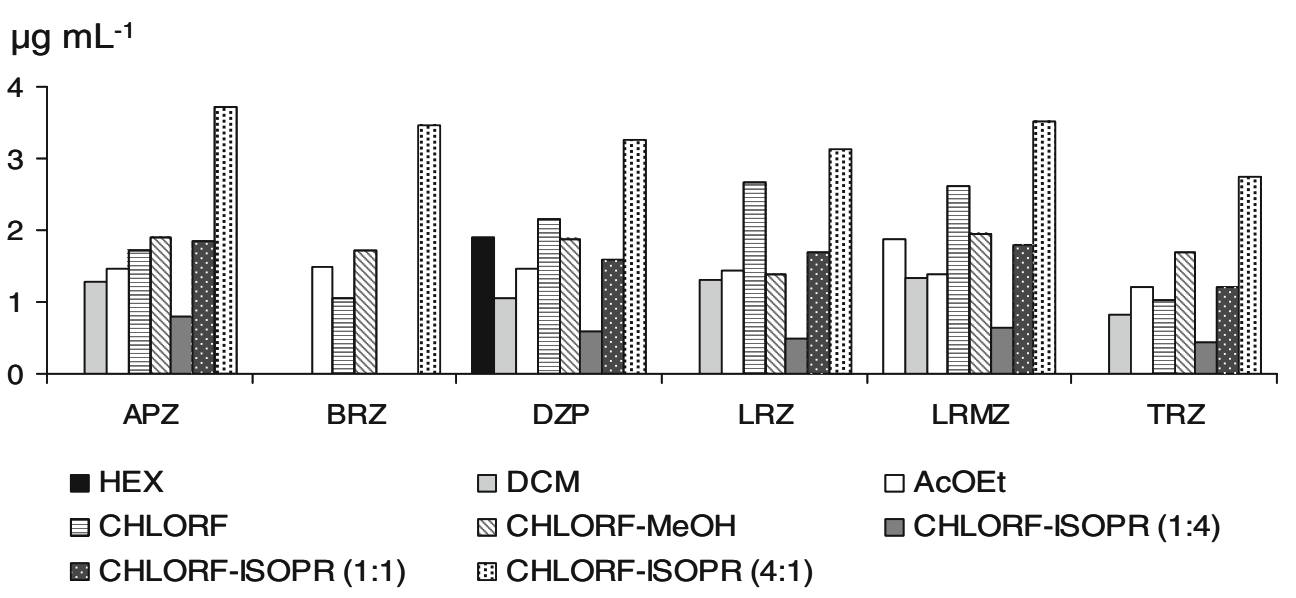

statistical package [42]. According to the preliminary study, chloroform/2-propanol $(4: 1, \mathrm{v} / \mathrm{v})$ and plasma/borate buffer (ratio 1:2) were two factors that were fixed. The MAE efficiency was evaluated through the BZD peak area obtained in each experiment. The estimates of the coefficients for the models were calculated by least-squares linear regression and these models were validated by analysis of variance (ANOVA). The constant term and the coefficients of the main effects (extraction time and solvent volume) were highly significant. The solvent volume was the most important factor, since it was statistically significant and positive for all BZD. The extraction time was also statistically significant for four BZD, with a positive effect for three of them, but with a negative effect for lorazepam. Some interactions and quadratic terms were statistically significant, presenting different effects (data not shown). Three-dimensional response surface plots show the effect of two variables on a given response, at a constant value of another variable (centre of the experimental domain). Figure 2 presents, as an example, some response surfaces developed by the model for two BZD. The best responses were obtained at a medium-high level of temperature and a high level of time for bromazepam (Fig. 2a) and alprazolam. However, lormetazepam, diazepam and tetrazepam show a different behaviour and better responses were acquired at a high level of time but a low level of temperature. For lorazepam, a higher response was obtained when temperature and time were at opposite levels. Also, better responses were achieved at a low level of time and a high level of solvent volume for all BZD. However, a dual behaviour was observed for alprazolam (Fig. 2b), lormetazepam and diazepam; in these cases, a high level of time and any solvent volume level also provided high responses. To find the optimal simultaneous conditions, multicriteria decision-making strategies using desirability function optimization were applied without additional experimentation. These desirability functions were built as partial Derringer functions for each BZD response by Nemrod(C) W [42]. The responses were transformed into a dimensionless desirability $\left(d_{i}\right)$ scale which ranged from $d=0$ for a completely undesirable response to $d=1$ for a fully desired response. In a second step, a global desirability function $(D)$, which represents the global quality of the common optimum, was calculated by combining single desirability functions, usually as the geometric mean. Further details can be found elsewhere [38]. The maximum $D$ obtained was 1.0 for $89^{\circ} \mathrm{C}, 13 \mathrm{~min}$ and $8 \mathrm{~mL}$ of chloroform/2-propanol $(4: 1, \mathrm{v} / \mathrm{v})$ mixture (Fig. 3). Under these conditions, the predicted values of $d_{i}$ were 1.0 for all drugs.
Fig. 2 Estimated response surface as a function of extraction time and temperature for BRZ (a) and as a function of solvent volume and time for APZ (b) obtained in microwaveassisted-extraction (MAE) optimization using a Doehlert design
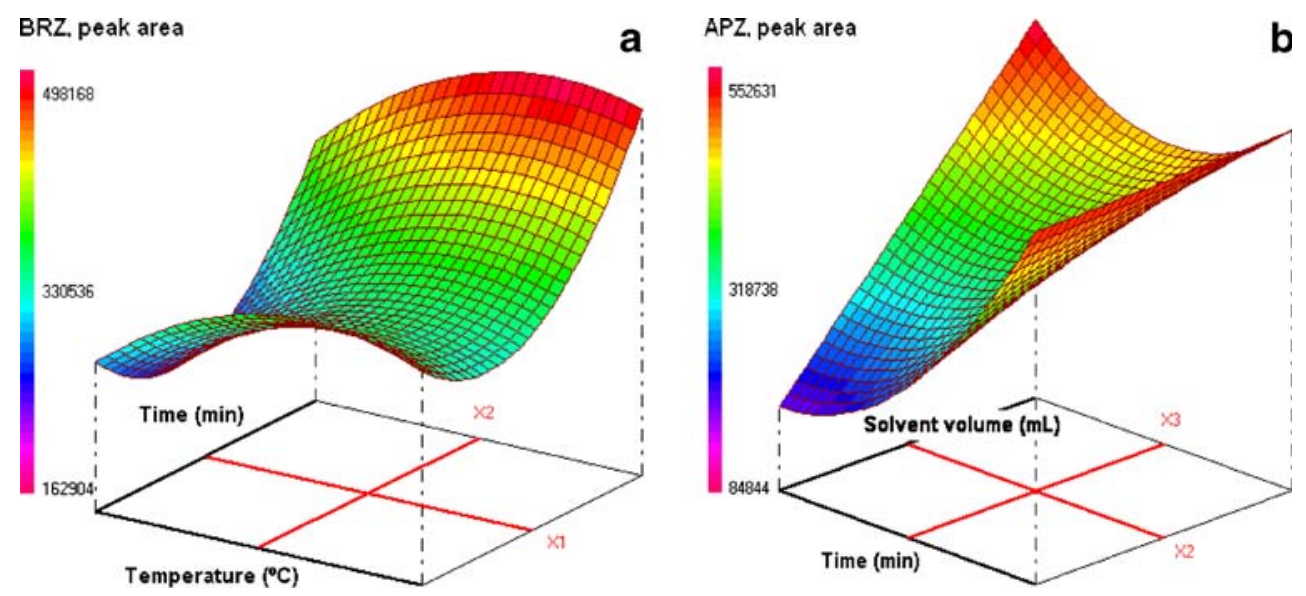

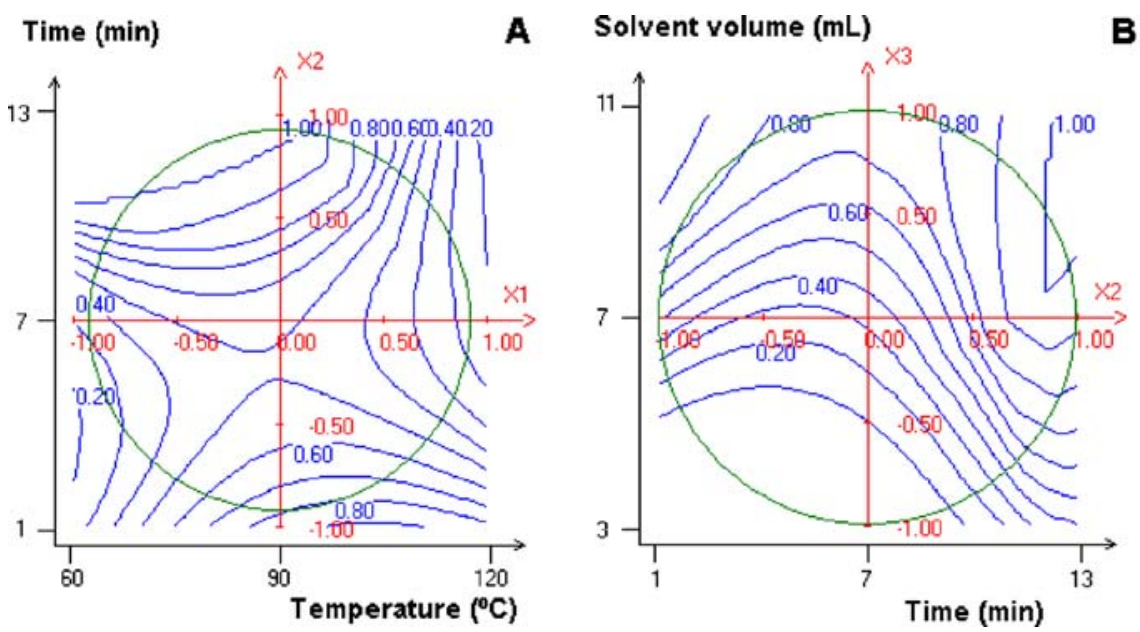

B Solvent volume $(\mathrm{mL})$



Fig. 3 Two-dimensional response surfaces of global desirability obtained in MAE optimization using a Doehlert design

Performance of the MAE-HPLC-DAD method

The proposed analytical method was validated according to the guiding principles of FDA [43] and ICH [44]. The analytes were identified from their retention times (viz. $7.66 \mathrm{~min}$ for bromazepam, $10.52 \mathrm{~min}$ for alprazolam, $13.70 \mathrm{~min}$ for lorazepam, $17.85 \mathrm{~min}$ for lormetazepam, $20.53 \mathrm{~min}$ for diazepam and $26.44 \mathrm{~min}$ for tetrazepam) and absorption spectra. Endogenous components in the biological matrix did not interfere with the analytes of interest (Fig. 4, chromatogram C) and, therefore, the proposed method was considered sufficiently selective for the determination of BZD in plasma samples.

The linearity was satisfactory for all compounds in the concentration range studied, with regression coefficients oscillating between 0.9997 and 0.9999 . Table 3 shows the
Fig. 4 Chromatograms resulting from a standard of $2 \mu \mathrm{g} \mathrm{mL} L^{-1}(a)$, a real case (containing BRZ and LRZ) (b) and a blank plasma $(c)$
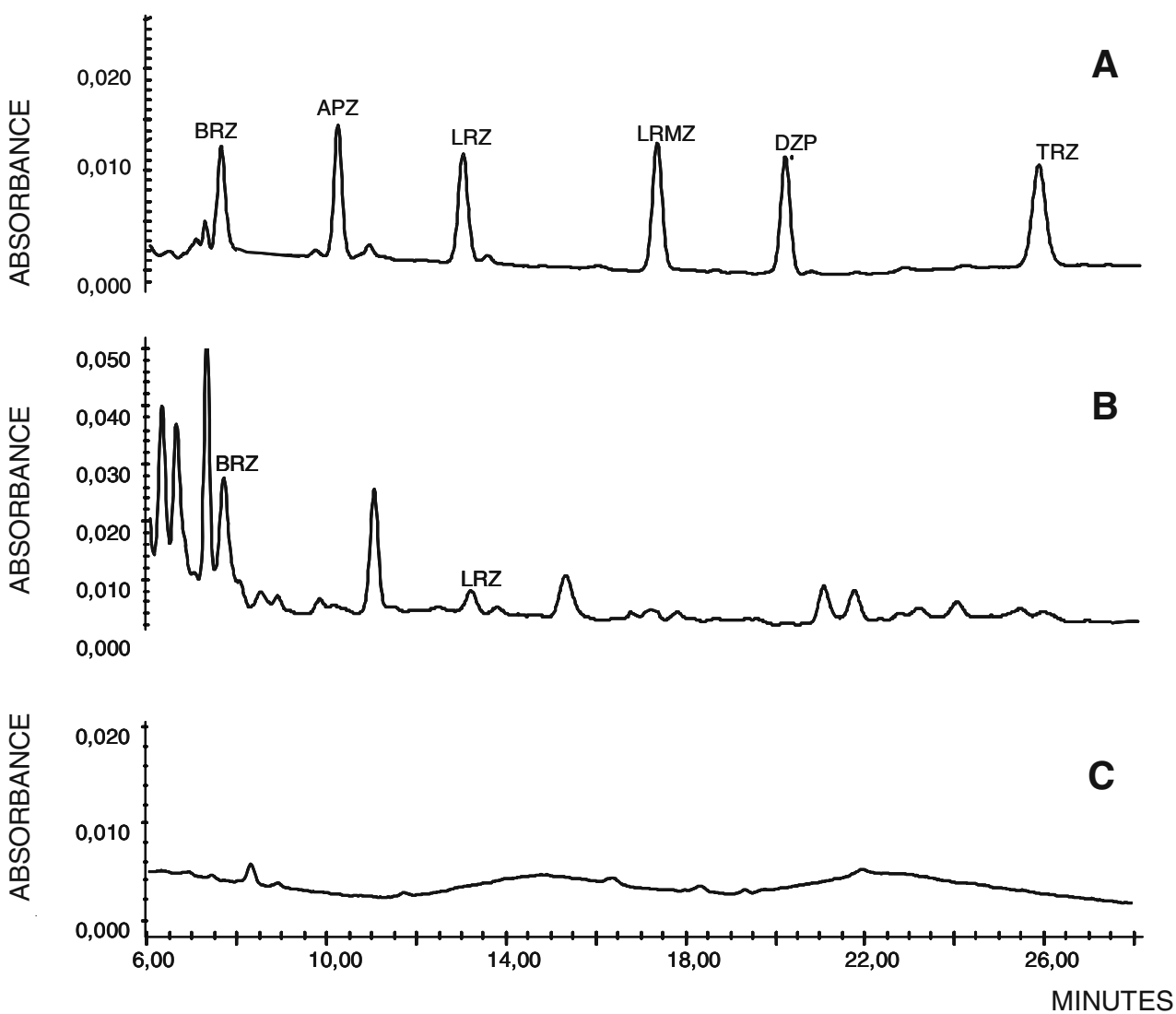
Table 3 Comparative analytical characteristics of the method for the determination of BZD in human plasma by SPE/microwave-assisted extraction $(M A E)$-HPLC-DAD

\begin{tabular}{|c|c|c|c|c|c|c|c|c|}
\hline \multirow[t]{2}{*}{ BZD } & \multicolumn{4}{|l|}{ SPE } & \multicolumn{4}{|l|}{ MAE } \\
\hline & $\begin{array}{l}\text { Slope } \\
\left(10^{5} \text { counts } \mathrm{mLng}^{-1}\right)\end{array}$ & $r$ coefficient & LOD $\left(\right.$ ngmL $\left.^{-1}\right)$ & LOQ $\left(\operatorname{ngmL}^{-1}\right)$ & $\begin{array}{l}\text { Slope } \\
\left(10^{5} \text { counts } \mathrm{mLng}^{-1}\right)\end{array}$ & $r$ coefficient & LOD $\left(\operatorname{ngmL}^{-1}\right)$ & LOQ $\left(\right.$ ngmL $\left.^{-1}\right)$ \\
\hline ALP & 1.42 & 0.9995 & 8.8 & 28.7 & 1.01 & 0.9998 & 7.4 & 24.7 \\
\hline BRZ & 1.10 & 0.9994 & 14.0 & 46.7 & 0.98 & 0.9998 & 10.4 & 34.7 \\
\hline DZP & 1.70 & 0.9999 & 10.0 & 33.3 & 1.10 & 0.9999 & 6.2 & 20.7 \\
\hline LRZ & 2.22 & 0.9995 & 12.0 & 40.0 & 1.04 & 0.9999 & 10.4 & 34.7 \\
\hline LRMZ & 2.25 & 0.9999 & 7.6 & 25.3 & 1.11 & 0.9997 & 7.2 & 24.0 \\
\hline TRZ & 1.47 & 0.9998 & 10.0 & 33.3 & 1.28 & 0.9998 & 12.6 & 42.0 \\
\hline
\end{tabular}

analytical characteristics of the method, calculated with SPE and MAE plasma extracts analysed by HPLC-DAD. The LOD was evaluated as the lowest concentration giving a chromatographic signal-to-noise ratio of 3 , and the limit of quantification (LOQ) was evaluated as the lowest concentration giving a chromatographic signal-to-noise ratio of 10 [45]. The LODs achieved ranged from 6.2 to $12.6 \mathrm{ng} \mathrm{mL}^{-1}$ and the LOQs obtained ranged from 20.7 to $42.0 \mathrm{ng} \mathrm{mL}$. Table 4 shows the recovery and precision (intraday and interday) for all BZD. The intraday precision ranged from 0.3 to $4.3 \%$ RSD and the interday precision ranged from 0.3 to $6.0 \% \mathrm{RSD}$. The mean recoveries ranged between $89.8 \pm$ 0.3 and $102.1 \pm 5.2 \%$.
Comparison between MAE and SPE

To test the statistical significance of SPE or MAE in calibration curves, ANOVA was applied to the calibration slopes obtained with both extraction procedures using the Statgraphics Centurion XV statistical package (Manugistics, Rockville, MD, USA). The results of the test showed that the variation in the calibration slopes of MAE or SPE was significant at the $95 \%$ confidence interval $(F=10.39$ and $p=$ 0.0234). Thus, SPE has a slightly higher sensitivity of calibration than MAE and only bromazepam and tetrazepam show similar calibration slope values for both extraction procedures. The data in Tables 3 and 4 show the relative

Table 4 Recovery and precision for analysis of BZD in fortified human plasma for SPE and MAE procedures

\begin{tabular}{|c|c|c|c|c|c|c|c|}
\hline \multirow[t]{2}{*}{ BZD } & \multirow[t]{2}{*}{ Parameters } & \multicolumn{3}{|c|}{$\operatorname{SPE}\left(\mu \mathrm{gmL}^{-1}, n=5\right)$} & \multicolumn{3}{|c|}{$\operatorname{MAE}\left(\mu \mathrm{gmL}^{-1}, n=5\right)$} \\
\hline & & 0.06 & 0.4 & 2 & 0.06 & 0.4 & 2 \\
\hline \multirow[t]{3}{*}{ APZ } & Recovery (\%) & $83.3 \pm 2.8$ & $87.9 \pm 5.9$ & $93.6 \pm 0.8$ & $102.1 \pm 5.2$ & $98.7 \pm 3.4$ & $97.3 \pm 0.8$ \\
\hline & Intraday RSD (\%) & 2.9 & 3.5 & 2.2 & 2.7 & 2.4 & 0.6 \\
\hline & Interday RSD (\%) & 3.4 & 6.8 & 0.9 & 5.1 & 3.5 & 0.8 \\
\hline \multirow[t]{3}{*}{ BRZ } & Recovery (\%) & $65.0 \pm 1.3$ & $81.0 \pm 3.7$ & $89.0 \pm 3.5$ & $100.8 \pm 6.0$ & $99.7 \pm 3.8$ & $98.2 \pm 1.7$ \\
\hline & Intraday RSD (\%) & 1.1 & 2.4 & 1.2 & 3.8 & 1.3 & 0.5 \\
\hline & Interday RSD (\%) & 2.0 & 4.6 & 0.4 & 6.0 & 3.9 & 1.8 \\
\hline \multirow[t]{3}{*}{ DZP } & Recovery (\%) & $99.7 \pm 4.7$ & $90.1 \pm 5.2$ & $94.3 \pm 0.7$ & $100.0 \pm 1.8$ & $94.3 \pm 2.0$ & $97.3 \pm 0.3$ \\
\hline & Intraday RSD (\%) & 4.8 & 5.5 & 3.3 & 3.9 & 2.1 & 1.0 \\
\hline & Interday RSD (\%) & 4.8 & 5.8 & 0.8 & 1.8 & 2.1 & 0.4 \\
\hline \multirow[t]{3}{*}{ LRZ } & Recovery (\%) & $76.6 \pm 3.0$ & $84.9 \pm 5.2$ & $87.2 \pm 1.4$ & $98.0 \pm 5.0$ & $97.3 \pm 3.4$ & $95.8 \pm 0.4$ \\
\hline & Intraday RSD (\%) & 1.6 & 5.3 & 2.6 & 1.8 & 3.3 & 0.3 \\
\hline & Interday RSD (\%) & 4.0 & 6.1 & 1.6 & 5.2 & 3.5 & 0.4 \\
\hline \multirow[t]{3}{*}{ LRMZ } & Recovery (\%) & $99.7 \pm 3.7$ & $93.4 \pm 6.0$ & $94.3 \pm 0.3$ & $98.4 \pm 5.3$ & $100.5 \pm 4.2$ & $98.4 \pm 0.3$ \\
\hline & Intraday RSD (\%) & 5.0 & 5.1 & 2.1 & 1.4 & 2.9 & 0.7 \\
\hline & Interday RSD (\%) & 3.8 & 6.5 & 0.8 & 5.4 & 4.2 & 0.3 \\
\hline \multirow[t]{3}{*}{ TRZ } & Recovery (\%) & $76.9 \pm 3.5$ & $82.1 \pm 4.1$ & $89.3 \pm 0.8$ & $99.0 \pm 2.7$ & $90.5 \pm 3.7$ & $89.8 \pm 0.3$ \\
\hline & Intraday RSD (\%) & 4.9 & 3.3 & 2.1 & 2.3 & 4.3 & 1.3 \\
\hline & Interday RSD (\%) & 4.6 & 5.0 & 0.9 & 2.8 & 4.1 & 0.3 \\
\hline
\end{tabular}

$R S D$ relative standard deviation 
effectiveness of both extraction procedures applied. All BZD except tetrazepam had lower LODs and LOQs for the MAE process. The precision was lower than $7 \%$ in all cases, but MAE slightly improved the RSD for the intraday and interday precision.

Two-way ANOVA was used to evaluate differences between recovery experiments $(n=5)$ of three factors: A, extraction procedures (MAE and SPE); B, six BZD analysed; $\mathrm{C}$, three concentrations $\left(0.06,0.4\right.$ and $\left.2 \mu \mathrm{g} \mathrm{mL} \mathrm{m}^{-1}\right)$. The significant differences of recovery means were compared by least-significant-difference methods at a confidence level of $95 \%$. No significant differences were found $(p>0.05)$ between the BZD analysed $(p=0.5622)$, the concentrations $(p=0.7059)$ and their interactions. No difference was observed between the recoveries obtained when one or another extraction procedure was applied to the BZD studied: interaction $\mathrm{AB}(p=0.5884)$. There was no significant difference between the recoveries obtained when one or another extraction procedure was applied at different concentrations: interaction AC $(p=0.5043)$. Finally, the extraction of BZD at different concentrations did not present any difference between the recoveries obtained: interaction $\mathrm{BC}$ $(p=0.9968)$. However, significant differences were found $(p<0.05)$ between the SPE and MAE recoveries $(F=7.01$ and $p=0.0111)$. The multiple range tests confirmed these results and showed that the recovery means obtained with SPE form a homogeneous group, significantly different from the MAE recovery means group, because the recoveries obtained with MAE were higher than those obtained when classic SPE was applied. Also, SPE gave higher data dispersion (from 65 to 103.7\%) than MAE (from 89.8 to $105.3 \%)$. According to the results of the ANOVA, the multiple range tests showed that the recovery means obtained at the three concentrations studied form a homogeneous group of means. Similarly the recovery means obtained for all BZD also form a homogenous group of means.

\section{Occurrence of BZD in human plasma samples}

The optimized MAE and the established SPE processes were applied to ten plasma samples from BZD users and then the samples were measured by HPLC-DAD.

The paired $t$ test was applied to compare the mean values from the two sample preparation procedures. The test is based on the paired differences between these two measurement values. The usual null hypothesis $\left(H_{0}\right)$ is that the difference in the mean values is zero [46]. The $t$ statistic is 2.239 for the $95 \%$ confidence interval and the $p=0.0610$. So $H_{0}$ is not rejected at $\alpha=0.05$ and statistical analysis confirmed that MAE and SPE do not provide significantly different results for the extraction of BZD. On the basis of this result, the optimized MAE-HPLC-DAD method is valid for routine toxicological analysis of plasma samples and it was applied to 17 plasma samples from patients undergoing therapy with BZD. In three of the 27 cases processed using MAE, two different BZD were found (bromazepam and lorazepam, diazepam and lorazepam, and tetrazepam and lorazepam). Moreover, BZD found in 12 cases shown toxic levels, whereas 18 cases showed therapeutic levels. The presence of lorazepam was demonstrated in 11 cases (range $41.6-783.8 \mathrm{ng} \mathrm{mL}^{-1}$; mean level $224.9 \mathrm{ng} \mathrm{mL}^{-1}$ ), followed by bromazepam in nine cases (range 61.6-414.4 ng mL ${ }^{-1}$; mean level $201 \mathrm{ng} \mathrm{mL}^{-1}$ ), alprazolam in seven cases (range $48.8-222 \mathrm{ng} \mathrm{mL}^{-1}$; mean level $118.5 \mathrm{ng} \mathrm{mL}^{-1}$ ), tetrazepam in two cases (range 73.8 $457.6 \mathrm{ng} \mathrm{mL}^{-1}$; mean level $265.7 \mathrm{ng} \mathrm{mL}^{-1}$ ) and diazepam in one case (level $241.2 \mathrm{ng} \mathrm{mL}^{-1}$ ). Figure 4 shows the chromatograms of a standard solution containing the six BZD at $2 \mu \mathrm{g} \mathrm{mL}^{-1}$, a real case (containing bromazepan and lorazepam) and a blank plasma.

\section{Conclusions}

MAE of human plasma samples is a powerful, fast and high-throughput extraction method. Regarding the total time of analysis, which nowadays is becoming one of the most important factors, MAE is faster than SPE, because 12 simultaneous extractions can be performed in a microwave oven. A simple, rapid and validated MAE-HPLC-DAD method was optimized for sensitive and appropriate determination of BZD in human plasma at therapeutic and toxic levels. The suitability of the method for the routine measurement of BZD in a toxicology laboratory was demonstrated. Furthermore, it can be assumed that the MAE method developed could be applicable to other BZD too.

\section{References}

1. Ashton CH (1995) Psychiatr Ann 25:158-165

2. United Nations (1997) Manual for use by national laboratories. Recommended methods for the detection and assay of barbiturates and benzodiazepines in biological specimens, ST/NAR/28. United Nations, Vienna

3. Marin SJ, Coles R, Merrell M, McMillin GA (2008) J Anal Toxicol 32:491-498

4. Lee X-P, Kumazawa T, Sato J, Shoji Y, Hasegawa C, Karibe C, Arinobu T, Seno H, Sato K (2003) Anal Chim Acta 492:223-231

5. Laurito TL, Mendes GD, Santagada V, Caliendo G, de Moraes MEA, De Nucci G (2004) J Mass Spectrom 39:168-176

6. Smink BE, Brandsma JE, Dijkhuizen A, Lusthof KJ, de Gier JJ, Egberts ACG, Uges DRA (2004) J Chromatogr B 811:13-20

7. Bugey A, Staub C (2007) J Sep Sci 30:2967-2978

8. Mercolini L, Mandrioli R, Amore M, Raggi MA (2008) J Sep Sci 31:2619-2626

9. Uddin MN, Samanidou VF, Papadoyannis IN (2008) J Sep Sci 31:3704-3717

10. He W, Parissis N, Kiratzidis T (1998) J Forensic Sci 43:1061-1067 
11. Wilhelm M, Battista HJ, Obendorf D (2001) J Anal Toxicol 25:250257

12. Adrian J, Gratacós-Cubarsí M, Sánchez-Baeza F, Garcia Regueiro J-A, Castellari M, Marco M-P (2009) Anal Bioanal Chem 395:1009-1016

13. Bugey A, Staub C (2004) J Pharm Biomed Anal 35:555-562

14. Uddin MN, Samanidou VF, Papadoyannis IN (2008) J Liq Chromatogr Relat Technol 31:1258-1282

15. He W, Parissis N (1997) J Pharm Biomed Anal 16:707-715

16. Hegstad S, Øiestad EL, Johansen U, Christophersen AS (2006) J Anal Toxicol 30:31-37

17. Fuh M, Lin S, Chen L, Lin T (2007) Talanta 72:1329-1335

18. Luo Y, Pan L, Pawliszyn J (1998) J Microcolumn Sep 10:193-201

19. Samanidou VF, Pechlivanidou AP, Papadoyannis IN (2007) J Sep Sci 30:679-687

20. Pirnay S, Bouchonnet S, Hervé F, Libong D, Milan N, d'Athis P, Baud F, Ricordel I (2004) J Chromatogr B 807:335-342

21. He H, Sun C, Wang X-R, Pham-Huy C, Chikhi-Chorfi N, Galons $\mathrm{H}$, Thevenin M, Claude J-R, Warnet J-M (2005) J Chromatogr B 814:385-391

22. Quintela O, Cruz A, de Castro A, Concheiro M, López-Rivadulla M (2005) J Chromatogr B 825:63-71

23. Gunnar T, Ariniemi K, Lillsunde P (2006) J Mass Spectrom 41:741-754

24. Hackett J, Elian AA (2006) Forensic Sci Int 157:156-162

25. Villain M, Concheiro M, Cirimele V, Kintz P (2005) J Chromatogr B 825:72-78

26. Redshaw CH, Cooke MP, Talbot HM, McGrath S, Rowland SJ (2008) J Soils Sediments 8:217-230

27. Anderson RA, Ariffin MM, Cormack PAG, Miller EI (2008) Forensic Sci Int 174:40-46

28. Cheng W-C, Yau T-S, Wong M-K, Chan L-P, Mok VK-K (2006) Forensic Sci Int 162:95-107
29. Miyaguchi H, Kuwayama K, Tsujikawa K, Kanamori T, Iwata YT, Inoue H, Kishi T (2006) Forensic Sci Int 157:57-70

30. Cudjoe E, Pawliszyn J (2009) J Pharm Biomed Anal 50:556-562

31. Chèze M, Villain M, Pépin G (2004) Forensic Sci Int 145:123-130

32. Sim es SS, Ajenjo AC, Franco JM, Vieira DN, Dias MJ (2009) Rapid Commun Mass Spectrom 23:1451-1460

33. Fernández P, Vázquez C, Lorenzo RA, Carro AM, Bermejo AM (2010) Anal Lett (in press)

34. De Koning S, Janssen HG, Brinkman UAT (2009) Chromatographia 69:S33-S78

35. Beyer A, Biziuk M (2008) Food Chem 108:669-680

36. Franke M, Winek CL, Kingston HM (1996) Forensic Sci Int 81:51-59

37. Madej K (2009) Trends Anal Chem 28:436-446

38. Lewis GA, Mathieu D, Phan-Tan-Luu R (1999) Pharmaceutical experimental design. Dekker, New York

39. Moffat AC, Osselton MD, Widdop B, Galichet LY (eds) (2004) Clarke's analysis of drugs and poisons in pharmaceutical, body fluids and post-mortem material. Pharmaceutical Press, London

40. Williams JR (2008) Bull World Health Organ 86:650-651

41. Kaufmann B, Christen P (2002) Phytochem Anal 13:105-113

42. Mathieu D, Nony J, Phan-Tan-Luu R (2001) Nemrod W, version 2001. LPRAI, Marseille

43. Food and Drug Administration (2001) U.S. Department of Health and Human Services, guidance for industry, bioanalytical method validation. http://www.fda.gov/downloads/Drugs/Guidance ComplianceRegulatoryInformation/Guidances/UCM070107.pdf

44. International Conference on Harmonization (2005) Validation of analytical procedures: methodology ICH Q2 B. http://www.ich. org/LOB/media/MEDIA417.pdf

45. Peters FT, Maurer HH (2002) Accred Qual Assur 7:441-449

46. Miller JN, Miller JC (2002) Estadística y quimiometría para química analítica, 4th edn. Prentice Hall, Madrid 